\title{
Morbidity and treatment in elderly patients surviving hospital admission with bleeding peptic ulcer
}

\author{
N Hudson, G Faulkner, S J Smith, R F A Logan, C J Hawkey
}

\section{Abstract}

Bleeding peptic ulcer in the elderly is associated with use of non-steroidal, anti-inflammatory drugs (NSAIDs) and aspirin, presenting a therapeutic dilemma for the treatment of survivors. To determine the longterm morbidity of patients surviving bleeding peptic ulcer and their treatment, with particular reference to NSAID use, this study followed up 487 patients aged over 60 years, who survived an episode of bleeding peptic ulcer in Nottingham during 1986 to 1991. Information was gathered by evaluation of general practitioner and hospital records, scrutiny of death certificates, and postal questionnaire to surviving patients. Of 487 patients surviving a bleeding peptic ulcer, 345 were alive at the follow up, a mean 34.2 months after discharge. Of these $201(58 \%)$ had taken NSAIDs before their ulcer bleed (104 non-aspirin NSAIDs, 77 aspirin, 20 both). Compared with non-users, the patients using NSAIDs at the time of presentation were significantly more likely subsequently to consult their general practitioner with locomotor symptoms $(56 \% v 35 \%, p<0.001)$ and receive further NSAIDs $(34 \% \quad v 13 \%, p<0.001)$, but significantly less likely to consult their general practitioner for dyspepsia (31\% $v$ $54 \%, p<0.001)$. Antiulcer drug use was widespread in both groups, with an overall point prevalence of $44 \%$. Seventy five patients received NSAIDs during the follow up period (69\% with coprescription of antiulcer drugs, usually $\mathrm{H}_{2}$ antagonists). Recurrent peptic ulcer, ulcer complications, and ulcer related deaths were uncommon. Antiulcer drug use was lower in those with ulcer recurrence compared with the point prevalence in those without $(17 \%$ v 44\%, p<0.05). Patient questionnaire responses confirmed a high level of locomotor symptoms especially in patients previously admitted with NSAID associated ulcer bleeding. In conclusion, in patients surviving peptic ulcer bleeding, recurrent ulcer complications and death seem to be lower than reported by studies that preceded the advent of antiulcer drugs. It is suggested that this low incidence may be a consequence of their use. Granted the low level of recurrent ulceration and the high level of locomotor symptoms in patients studied, current treatment may unduly emphasise the importance of stopping NSAIDs in this group of patients.

(Gut 1995; 37: 182-186)

Keywords: non-steroidal anti-inflammatory drugs, aspirin, peptic ulcer complications, $\mathrm{H}_{2}$ antagonists, arthritis.

Bleeding peptic ulcer continues to be a common problem, being the cause of about 25000 hospital admissions and 2500 deaths annually in the United Kingdom. Patients who survive an episode of peptic ulcer bleeding have been reported to have a high frequency of further complications. ${ }^{1-9}$ Indirect evidence suggests that this risk may have diminished since the advent and widespread use of $\mathrm{H}_{2}$ receptor antagonists ${ }^{10}$ but it is not known how this has influenced the treatment and subsequent morbidity of these patients in the community at large. Equally, non-steroidal anti-inflammatory drugs (NSAIDs), comprising aspirin and non-aspirin NSAIDs now account for more than half of all peptic ulcer bleeding in the elderly. ${ }^{11} 12$ Traditional advice that such drugs are often unnecessary ${ }^{13}$ and should anyway be stopped in such patients is supported by a study suggesting that most elderly patients can stop taking NSAIDs without subsequent deterioration in their locomotor symptoms. ${ }^{14}$ It is not known, however, when NSAIDs are stopped after a peptic ulcer bleed, whether patients suffer in consequence or to what extent the drugs have to be restarted. The aim of this study was to record the subsequent treatment and symptoms in two groups of patients surviving an acute upper gastrointestinal bleed, those taking NSAIDs before their admission and those not taking these drugs at the time of admission, and to determine the consequences of this treatment.

\section{Methods}

All patients aged 60 years or over admitted to the Nottingham University and City Hospitals between April 1986 and January 1991 with an acute upper gastrointestinal haemorrhage resulting from endoscopically confirmed peptic ulceration were considered for inclusion. Acute upper gastrointestinal haemorrhage was defined as haematemesis or melaena, or both, or collapse subsequently found to be caused by a bleeding peptic ulcer. Patients were interviewed by a single trained interviewer according to a structured eight page questionnaire on 
TABLE I Subsequent locomotor symptoms and treatment according to NSAID status at the time of original admission

\begin{tabular}{lcc}
\hline & \multicolumn{2}{l}{ Original status } \\
\cline { 2 - 3 } & $\begin{array}{l}\text { NSAID users } \\
(n=187)\end{array}$ & $\begin{array}{c}\text { Non-users } \\
(n=129)\end{array}$ \\
\hline GP consultations for locomotor & & \\
$\quad$ symptoms (\%) & $104(56)$ & $45(35)$ \\
No of consultations & $58(32)$ & $31(24)$ \\
1 & $26(14)$ & $11(9)$ \\
$2-3$ & $13(7)$ & 3 \\
4 or more & $7(3)$ & 0 \\
GP consultations & & \\
+ hospital referral/orthopaedic & $162(87)$ & $69(48)$ \\
$\quad$ surgery & $58(34)$ & $17(13)$ \\
No requiring analgesia (\%) & $49(26)$ & $15(8)$ \\
Total NSAIDs & 2 & 0 \\
Non-aspirin NSAIDs & 7 & 2 \\
Full dose aspirin & $89(48)$ & $50(39)$ \\
Low dose aspirin & & \\
Other analgesia (\%) &
\end{tabular}

One of the original NSAID users received NSAIDs and other analgesia in the follow up period.

personal details, medical history, and drug use. In all cases consent was obtained before interview. The subsequent status of patients who were alive 30 days after their original admission was determined in January 1992. In each case the general practitioners' records were examined by the same trained interviewer (GF) using a structured proforma to collect data on peptic ulcer recurrence and complications, general practitioner consultations for dyspeptic and arthritic symptoms, subsequent management of symptoms, and any hospital referrals. Information was also obtained on prescriptions for each patient including repeat and current prescriptions. Patients believed to be capable of responding were also posted a three page questionnaire enquiring as to their general health, arthritic and dyspeptic symptoms, previous and current drug treatment, and the adequacy of therapy in symptom relief. The questionnaire asked specifically and separately about general practitioner consultations for dyspepsia and locomotor symptoms. The $\chi^{2}$ test with Yates's correction was used to determine statistical differences in characteristics between patient groups.

\section{Results}

Patients

Six hundred and forty eight patients were

TABLE II Subsequent dyspeptic symptoms and treatment according to NSAID status at the time of original admission

\begin{tabular}{lcc}
\hline & \multicolumn{2}{c}{ Original status } \\
\cline { 2 - 3 } & $\begin{array}{l}\text { NSAID users } \\
(n=187)\end{array}$ & $\begin{array}{c}\text { Non-users } \\
(n=129)\end{array}$ \\
\hline GP consultations for dyspepsia (\%) & $58(31)$ & $70(54)$ \\
No of consultations & $42(22)$ & $48(35)$ \\
1 & $16(9)$ & $16(13)$ \\
$2-3$ & 0 & $6(5)$ \\
4 or more & $174(93)$ & $121(94)$ \\
No requiring antiulcer & & \\
drugs healing drugs (\%) & $164(88)$ & $116(90)$ \\
Type of drug & 6 & 1 \\
H antagonists (\%) $_{\text {Misoprostol }}$ & 13 & 14 \\
Omeprazole & 4 & 0 \\
Antacids alone & 3 & 0 \\
Others & & \\
\hline
\end{tabular}

Some patients received more than one type of antiulcer drug. admitted with an endoscopic diagnosis of bleeding peptic ulcer between April 1986 and January 1991. Of these 73 died before interview was possible, 33 were too confused to give an interview, two refused, and for 40 the interviewer was unavailable. This left 500 patients who were interviewed while in hospital. Of these, 13 died between interview and discharge from hospital leaving 487 who were alive 30 days after admission. During a subsequent mean follow up period of $34 \cdot 2$ months (SD 15.5 months) there were a further 142 deaths (29\%), which are discussed in the accompanying paper (see page 177-81). The general practitioner notes of 316 of 345 survivors were scrutinised to determine treatment after the index admission (187 previous NSAID users, 129 previous non-users). Data on 29 patients were not available because they were not resident in the Nottingham area at the time of study. Postal questionnaires were sent to 283 of 316 patients whose general practitioners records had been scrutinised. A total of 33 patients were not approached because they were considered to be incapable of responding because of infirmity, confusion or dementia. Two hundred and fifty eight patients $(91 \%)$ returned the postal questionnaire (158 previous NSAID users and 100 previous non-users).

\section{Subsequent symptoms}

One hundred and four (56\%) of the previous NSAID users subsequently consulted their general practitioner with problems related to their locomotor system compared with 45 $(35 \%)$ of previous non-users (Table I, $\left.\chi^{2}=12.35, p<0.001\right)$. Thirty nine $(21 \%)$ of the previous users consulted their general practitioner more than once compared with $14(11 \%)$ of previous non-users $\left(\chi^{2}=4 \cdot 78\right.$, $\mathrm{p}<0.05)$. Seven required hospital referral or orthopaedic surgery compared with none of the previous non-users. Conversely consultations for dyspepsia were more common among previous non-users than previous users (Table II, $54 \%$ v 31\%, $\chi^{2}=16 \cdot 17$, $\mathrm{p}<0.001$ ), and there were significantly more patients with two or more consultations $\left(\chi^{2}=5 \cdot 42, \mathrm{p}<0 \cdot 02\right)$.

\section{Subsequent NSAID therapy}

Fifty eight of the previous users (34\%) subsequently received prescriptions for NSAIDs after their index admission compared with 17 previous non-users $(13 \%) \quad\left(\chi^{2}=22 \cdot 21\right.$, $\mathrm{p}<0.001$, Table I). In these previous NSAID users most prescriptions ( $83 \%$ ) were for nonaspirin NSAIDs rather than aspirin and 38 of these patients $(49 \%)$ received such prescriptions on at least three occasions. Prescriptions of analgesic drugs other than NSAIDs were slightly more common in previous users than non-users $(48 \% v 39 \%$, NS). At the time when the general practitioner records were examined 21 subjects $(6 \cdot 6 \%)$ were receiving NSAIDs comprising non-aspirin NSAIDs (11) or aspirin (10) and 99 (31\%) other forms of analgesia. 
TABLE III Subsequent peptic ulcer complications during the follow up period

\begin{tabular}{|c|c|c|c|c|c|c|}
\hline & \multicolumn{2}{|c|}{ Original status } & \multicolumn{2}{|c|}{$\begin{array}{l}\text { Subsequent } \\
\text { NSAID use }\end{array}$} & \multicolumn{2}{|c|}{$\begin{array}{l}\text { Antiulcer drug } \\
\text { use at time of } \\
\text { ulcer recurrence }\end{array}$} \\
\hline & $\begin{array}{l}\text { NSAID } \\
\text { user }\end{array}$ & $\begin{array}{l}\text { Non- } \\
\text { user }\end{array}$ & + & - & + & - \\
\hline $\begin{array}{l}\text { Number } \\
\text { All confirmed ulcer recurrences* } \\
\text { Ulcer bleeding } \\
\text { Ulcer perforation } \\
\text { Ulcer related deaths }\end{array}$ & $\begin{array}{c}274 \ddagger \\
12 \\
8 \\
0 \\
3\end{array}$ & $\begin{array}{c}1845 \\
17 \\
9 \\
2 \\
5\end{array}$ & $\begin{array}{r}75 \\
4 \\
3 \\
0 \\
1\end{array}$ & $\begin{array}{r}383 \\
25 \\
14 \\
2 \\
7\end{array}$ & $\begin{array}{l}5 \\
2 \dagger \\
1 \\
2 \dagger\end{array}$ & $\begin{array}{r}24 \\
15 \\
1 \\
6\end{array}$ \\
\hline
\end{tabular}

*As evidence by endoscopy, barium meal or death certificate; fone patient had been taking $\mathrm{H}_{2}$ antagonists until two weeks before presentation leading to death; fincluding 87 patients who died; Sincluding 55 patients who died.

\section{Subsequent antiulcer treatment}

Most patients received antiulcer treatment on discharge from hospital after their gastrointestinal bleed (Table II) and 128 (44\%) were still taking antiulcer drugs at the time of assessment. These comprised $77(41 \%)$ of the previous NSAID users and $62(48 \%)$ of previous non-users. One hundred and thirty eight patients $(44 \%)$, comprising $74(40 \%)$ of previous NSAID users, and $64(50 \%)$ or previous non-users, remained taking antiulcer treatment for at least one year. $\mathrm{H}_{2}$ antagonists were by far the commonest antiulcer drugs used irrespective of ulcer type or whether the patients were NSAID users or non-users at the time of original admission. There were no significant differences in either the types of ulcer treatment used or the length of prescription time between previous NSAID users and non-users.

\section{Concomitant antiulcer and NSAID treatment}

Overall $51(69 \%)$ of the 75 subjects who were prescribed aspirin or NSAIDs after their bleed received concomitant coprescription of antiulcer prophylactic agents. Of the patients who did not receive concomitant prophylaxis, seven were receiving low dose aspirin and 14 received a variety of NSAIDs, nine subjects receiving them on at least three occasions. Few patients received misoprostol (six in total), even among those previous users of NSAIDs who were subsequently restarted on these drugs despite these patients being in what is thought to be a high risk group.

\section{Subsequent peptic ulceration}

Twenty nine patients experienced an ulcer recurrence (Table III). In 19 this second presentation was with an ulcer complication (ulcer bleeding in 17 and perforation in two). Ulcer recurrence was somewhat less likely in previous NSAID users than non-users $(4 \cdot 4 \% v$ $\left.9.3 \%, \quad \chi^{2}=3.602,0.05<\mathrm{p}<0.1\right)$. Likewise, $2.9 \%$ of previous users experienced ulcer bleeding or perforation in the follow up period compared with $6.0 \%$ of previous non-users, but this difference did not reach significance $\left(\chi^{2}=1 \cdot 88, \mathrm{NS}\right)$.

Only five of those with ulcer recurrence $(17 \%)$ were taking antiulcer drugs at the time of this recurrence, significantly less than the $44 \%$ prevalence of use in the 316 surviving patients at the time of examination of the general practitioner records $\left(\chi^{2}=5 \cdot 72, p<0.02\right)$. The difference remained significant if the analysis was restricted to patients presenting with ulcer complications. Four patients with ulcer recurrence $(14 \%)$ were taking NSAIDs at the time of re-presentation compared with $6.6 \%$ of survivors at the time of examination of general practitioner records. This difference did not reach significance $\left(\chi^{2}=1 \cdot 07\right)$. Only one of these four patients was receiving concurrent antiulcer treatment. Overall only one of 75 patients who used NSAIDs during the follow up period died of an ulcer complication (1.3\%), a patient taking low dose aspirin who suffered a recurrent ulcer bleed, compared with $1.8 \%$ of those not using the drugs.

\section{Patient questionnaire}

When patients themselves were asked about their health 132 of 158 previous NSAID users admitted to suffering locomotor symptoms at some time during the follow up period (84\%) compared with 65 of 100 previous non-users $(65 \%)\left(\chi^{2}=10.66, p<0.01\right.$, Table IV $)$. This was consistent with the data on general practitioner consultations for locomotor symptoms, although patients reported a higher level of symptoms than recorded by their general practitioners.

In $52(33 \%)$ of the 158 previous NSAID users arthritic pain was such that it was reported to interfere with daily activities compared with $15(15 \%)$ of the 100 previous nonusers $\left(\chi^{2}=9.31, \mathrm{p}<0.01\right)$. Of the previous NSAID users $62 \%$ said they took regular analgesia of some form for locomotor symptoms compared with $37 \%$ of previous non-users $\left(x^{2}=14.39, \mathrm{p}<0.001\right)$. This use was largely among previous uses of non-aspirin NSAIDs 85 of $103(82 \%)$ compared with 13 of 55 $(24 \%)$ who were receiving aspirin at initial presentation $\left(\chi^{2}=50.32, p<0.001\right)$.

Patients were also asked whether their subsequent analgesic treatment controlled their symptoms adequately. Only $28 \%$ ( $18 \%$ ) of the respondents who previously used NSAIDs and reported subsequent locomotor symptoms felt that their subsequent (largely non-NSAID) treatment provided pain relief all the time and $50(38 \%)$ felt pain was not ever controlled adequately with the drug treatment they were given. Among the smaller number of previous non-users with arthritic symptoms the proportions were similar. Thus, overall $32 \%$ of all

TABLE IV Results of patient questionnaire-locomotor symptoms

\begin{tabular}{lll}
\hline & \multicolumn{2}{l}{ Original status } \\
\cline { 2 - 3 } & $\begin{array}{l}\text { NSAID users } \\
(n=158)\end{array}$ & $\begin{array}{l}\text { Non-users } \\
(n=100)\end{array}$ \\
\hline Patients reporting locomotor & $132(84)$ & $65(65)$ \\
$\quad \begin{array}{l}\text { symptoms (\%) } \\
\text { Frequency and severity }\end{array}$ & $26(16)$ & $23(23)$ \\
Occasional & $11(7)$ & $3(3)$ \\
Weekly & $43(27)$ & $24(24)$ \\
Daily not interfering with activity & $52(33)$ & $15(15)$ \\
Daily interfering with activity & $98(62)$ & $37(37)$ \\
Drug treatment & 14 & 4 \\
Any analgesics (\%) & 1 & 1 \\
Non-aspirin NSAIDs & 83 & 32 \\
Aspirin & & \\
Other analgesia &
\end{tabular}


TABLE V Patient questionnaire - dyspeptic symptoms and treatment

\begin{tabular}{lll}
\hline & \multicolumn{2}{l}{ Original status } \\
\cline { 2 - 3 } & $\begin{array}{l}\text { NSAID users } \\
(n=158)\end{array}$ & $\begin{array}{c}\text { Non-users } \\
(n=100)\end{array}$ \\
\hline $\begin{array}{l}\text { Patients with dyspeptic } \\
\text { symptoms (\%) }\end{array}$ & $98(62)$ & $70(70)$ \\
$\begin{array}{l}\text { Frequency } \\
\text { Infrequently }\end{array}$ & $57(36)$ & $38(38)$ \\
$\quad$ Frequently & $4(3)$ & $9(9)$ \\
$\quad$ Daily & $37(23)$ & $23(23)$ \\
Treatment & $64(41)$ & $37(37)$ \\
$\quad$ Self treatment & $28(18)$ & $30(30)$ \\
$\quad$ Consult GP & $9(6)$ & $6(6)$ \\
\hline Hospital referral & &
\end{tabular}

`These patients are also recorded under 'Consult GP'. Data on treatment in nine patients with dyspepsia was not available.

patients taking NSAIDs before their index bleed subsequently suffered locomotor symptoms that they reported were not adequately controlled by the pain relief they received compared with $12 \%$ of patients not taking NSAIDs before their bleed $\left(\chi^{2}=11 \cdot 89, \mathrm{p}<0 \cdot 001\right)$.

Dyspeptic symptoms were reported by $65 \%$ of patients, with no significant differences between previous users $(62 \%)$ or non-users $(70 \%)$ (Table V). These symptoms led to a consultation with the general practitioner, however, in $18 \%$ of previous NSAID users compared with $30 \%$ of previous non-users $\left(\chi^{2}=4.62, \mathrm{p}<0.05\right)$. These results again were consistent with the information obtained from the general records although patients reported a higher level of symptoms than were recorded by the general practitioner.

\section{Discussion}

Previous studies have suggested that patients who present with ulcer bleeding are at increased risk of further ulcer complications. ${ }^{1-9}$ How to reduce this risk is unclear, particularly for patients taking NSAIDs. The primary aims of our study were to describe the treatment approaches adopted for defined groups of patients and to investigate associated outcomes.

Our results show that patients fell into two broad categories. The general practitioner records show that those who were not taking NSAIDs when the index bleed occurred has a high likelihood of further consultation with their general practitioner for continuing dyspepsia during the follow up period. Seventy per cent of patients reported dyspepsia regardless of their initial group, compatible with a high level of reporting of comparatively trivial symptoms. Those whose initial bleed was not associated with NSAIDs, however, confirmed the higher consultation rate, compatible with the suggestion that they experienced more significant dyspepsia subsequently.

In contrast with these patients those whose ulcer bleed occurred in association with NSAID consumption made fewer consultations for dyspepsia but had a high prevalence of locomotor symptoms. One third reported locomotor symptoms sufficient to interfere with daily activates and about two thirds took regular analgesia. Most received non-NSAID analgesia but a third found that it did not provide adequate pain relief. Nearly a third required further NSAID treatment and 3\% were referred to hospital because of continuing locomotor symptoms. For understandable reasons, NSAIDs are usually stopped if patients who take them develop a bleeding peptic ulcer. Our results suggest that the symptomatic costs of such a policy are higher than previously recognised. In addition they affect a wide group of patients, as only 31 of the original series of 487 patients carried the diagnosis of rheumatoid arthritis.

There was widespread use of antiulcer drug treatment, principally $\mathrm{H}_{2}$ receptor antagonists, during the follow up period, regardless of whether the patients were initially taking NSAIDs or not. The point prevalence of such drug use was $42 \%$. This implies an annual drug cost in the range $£ 44.00$ to $£ 218.00$ per patient per anum, based on daily costs of standard doses of antiulcer drugs of between $26 \mathrm{p}$ and $£ 1.30$. During the follow up period the rate of ulcer recurrence, complication, and mortality was comparatively low, and seemed to be less than reported by studies conducted before the advent of $\mathrm{H}_{2}$ receptor antagonists, when about half of the patients who presented with ulcer bleeding and were treated medically could expect to suffer another bleeding episode during the ensuring $10-15$ years. ${ }^{1-9}$

It seems plausible that the low ulcer recurrence and complication rate is caused by the widespread use of $\mathrm{H}_{2}$ receptor antagonists that we observed in our study. Although methodological differences obviously exist, the ulcer recurrence rate in our study was similar to, or even lower than those reported in maintenance trials of $\mathrm{H}_{2}$ receptor antagonists. ${ }^{15}$ Likewise a recent audit of re-ulceration in patients maintained with ranitidine has suggested a low rate of ulcer relapse and a particularly low rate of ulcer complications. ${ }^{10}$ In our study, among those patients who did develop further ulcer recurrence or complications, antiulcer drug use at the time of re-presentation was significantly less than in the group as a whole at the time of inspection of the general practitioners records. There were too few ulcer deaths for this difference to have arisen by a process of attrition, and any prescribing bias towards patients with more aggressive ulcer disease would act to make our evaluation of these differences a conservative one. Although considerable caution is needed in interpreting these results because of the small numbers involved a probable explanation for the findings is that the widespread use of antiulcer drugs protected our patients against ulcer recurrence and the development of further ulcer complications.

Patients previously admitted with NSAID associated ulcer bleeds had if anything a lower ulcer recurrence rate during the follow up period than previous non-users. Conversely, NSAID use during the follow up period was associated with a slight but not significant increase in ulcer recurrence. Even in this group, however, the rate of ulcer relapse was very low (four episodes). The number of events was too small to find out if this low relapse rate was also 
associated with use of antiulcer drugs in this subgroup but the data are at least consistent with this possibility, as only one of four patients was taking antiulcer drugs at the time of relapse, compared with a $70 \%$ coprescribing rate for the subgroup as a whole.

Our cohort of patients was recruited over a five year period during which significant changes in prescribing practice have occurred. Misoprostol was available during the period of our study, but its use was too low to comment on any value. A number of patients were taking low dose aspirin. This treatment is now recognised to be associated with an increased risk of ulcer bleeding, but use will probably increase further. ${ }^{16}$ Eradication of Helicobacter pylori is increasingly pivotal in the treatment of nonNSAID patients, including those who present with ulcer bleeding. ${ }^{17} 18$ Although our study was a survey of treatment practice rather than one randomised controlled trial, our results suggest that a further change in treatment, for NSAID patients, would be worth evaluating. We have shown on the one hand that stopping NSAIDs in this group is associated with a high prevalence of locomotor symptoms and on the other hand that further use of NSAIDs (usually in the context of coadministration of an antiulcer drug) is not associated with a catastrophic level of ulcer complications. A controlled comparison of the effects of NSAID cessation or NSAID continuation with concurrent prophylaxis on morbidity and quality of life would seem to be worthwhile.

1 Boles RS Jr, Cassidy WJ, Jordon SM. Medical versus surgical management for the complication of haemorrhage in duodenal ulcer. Gastroenterology 1957; 32: 52-9.
2 Arias IM, Zamcheck N, Thrower WB. Recurrence of haemorrhage from medically treated gastric ulcers: 4-year to 8-year follow-up of 47 patients. Arch Intern Med 1958; 101: 369-76.

3 Serebro HA, Mendeloff AI. Late results of medical and surgical treatment of bleeding peptic ulcer. Lancet 1966; ii: $505-8$.

4 Borland JL, Sr Hancock WR, Borland JL Jr. Recurrent upper gastrointestinal haemorrhage in peptic ulcer. Gastroenterology 1967; 52: 631-7.

5 Harvey RF, Lanmang MJS. The late results of medical and surgical treatment for bleeding duodenal ulcer. $Q \mathcal{F} \mathrm{Med}$ 1970; 39: 539-47.

6 Hallenbeck GA. Elective surgery for treatment of haemorrhage from duodenal ulcer. Gastroenterology 1970; 59: 784-9.

7 Johansson C, Barany F. A retrospective study on the outcome of massive bleeding from peptic ulceration. Scand come of massive bleeding from

8 Doyle DV, Dieppe PA, Scott J, Huskisson EC. An articular index for the assessment of osteoarthritis. Ann Rheum Dis 1981; 40: 75-8.

9 Macleod IA, Mills PR. Factors identifying the probability of further haemorrhage after acute upper gastrointestinal haemorrhage. $B r \mathcal{F}$ Surg 1982; 69: 256.

10 Wyllie JH, Clark CG, Alexander-Williams J, Bell PRF, Kennedy TL, Kirk RM, et al. Effect of cimetidine on surgery for duodenal ulcer. Lancet 1981; i: 1307-8.

11 Hawkey CJ. Non steroidal anti-inflammatory drugs and peptic ulcers. $B M \Im 1990 ; 300: 278-84$

12 Gabriel SE, Jaakkimainen L, Bombardier C. Risk for serious gastrointestinal complications related to use of non gastrointestinal complications related to use of non steroidal anti-inflammatory dru

13 Bradley JD, Brandt KD, Katz BP, Kalasinski LA, Ryan SI. Comparison of an anti-inflammatory dose of ibuprofen, an analgesic dose of ibuprofen and acetaminophen in the treatment of patients with osteoarthritis of the knee. $N$ Engl f Med 1992; 325: 87-91.

14 Jones AC, Berman P, Doherty $M$. Non steroidal antiinflammatory drug usage and requirement in elderly acute hospital admissions. Br f Rheumatol 1992; 31: 45-8.

15 Gough KR, Korman MG, Bardhan KD, Lee FI, Crowe JP, Reed PI, et al. Ranitidine and cimetidine in prevention of duodenal ulcer relapse. Lancet 1984; ii: 659-62.

16 Steering Committee of the Physicians' Health Study Research Group. Final report on the aspirin component of Research Group. Final report on the aspirin component of
the ongoing physicians' health study. $N$ Engl $f$ Med 1989; 321: 131-5.

17 Graham DY, Hepps KS, Ramirez FC, Lew GM. Treatment of $\mathrm{H}$ pylori reduces the rate of rebleeding in peptic ulcer disease. Scand 7 Gastroenterol 1993; 28: 939-42.

18 Labeiz J, Gyeres E, Ruhi GH, Borsch G. Role of $H$ pylori eradication in patients with peptic ulcer bleeding. Gastroenterology 1993; 104: A126. 